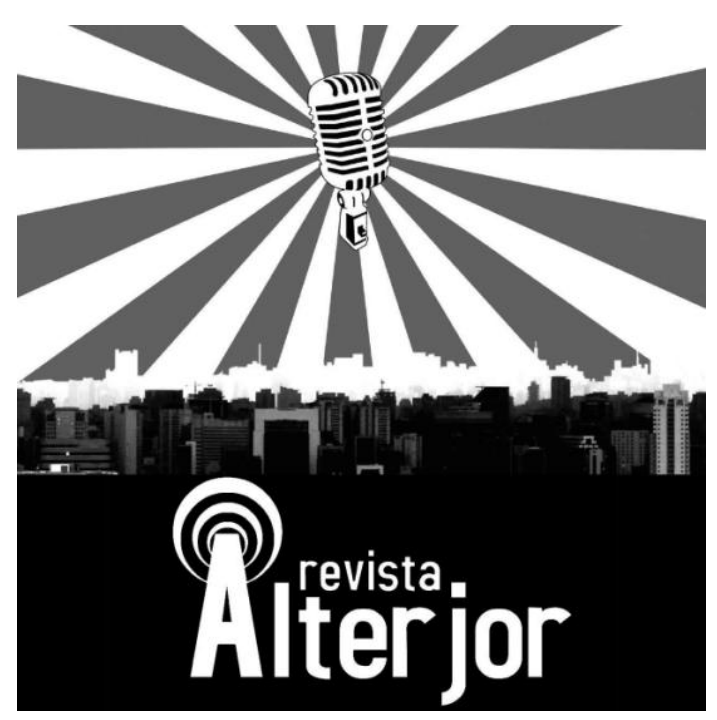

\title{
A MEMÓRIA DO TELEJORNALISMO: TRANSFORMAÇÕES TECNOLÓGICAS E CULTURAIS DO ARQUIVAMENTO, ACESSO E USO DO ARQUIVO DE IMAGEM NA INTERNET
}

José Jullian Gomes de Souza ${ }^{1}$

RESUMO: Esta pesquisa explana sobre as transformações nos processos de preservação da memória do telejornalismo, objetivando compreender o arquivamento, acesso e uso da imagem telejornalística no âmbito on-line. O objetivo geral é identificar as transformações, desafios e oportunidades das inovações tecnológicas, frente ao processo histórico de suportes de armazenamento audiovisual. A metodologia perpassa uma abordagem qualitativa, pesquisa bibliográfica e estratégia de pesquisa exploratória-descritiva, discorrendo sobre essas transformações e apresentando o Projeto Memória Globo como um lugar de memória audiovisual e jornalístico no universo digital. Identifica-se que os processos de arquivamento, acesso e uso das imagens têm passado por um processo de ressignificação das mídias analógicas para as mídias digitais.

\section{PALAVRAS-CHAVE: Telejornalismo. Arquivamento. Memória.}

ABSTRACT: This research explains about the transformations in the television news memory preservation processes, aiming to understand the archiving, access and use of the television news image online. The following question is problematic: how did technological and socio-cultural transformations show the need for new forms of archiving audiovisual information in digital information environments? The general objective is to identify the transformations, challenges and opportunities of technological innovations, in view of the historical process of audiovisual storage media. The methodology runs through a qualitative approach, bibliographic research and exploratory-descriptive research strategy, discussing these transformations and presenting the Globo Memory Project as a place of audiovisual and journalistic memory in the digital universe. It identified that the processes of archiving, accessing and using archival news images have gone through a process of opening and reframing analog media for the advent of digital media and changes caused by the sharing of memory on the internet.

KEYWORDS: Telejournalism. Archiving. Memory.

\footnotetext{
${ }^{1}$ Jornalista pela Universidade Federal do Ceará. Mestre em Biblioteconomia pelo Programa de PósGraduação em Biblioteconomia da Universidade Federal do Cariri. Membro do Centro de Estudos e Pesquisa em Jornalismo (CEPEJor). E-mail: jullianjose64@gmail.com.
}

Revista ALTERJOR

Grupo de Estudos Alterjor: Jornalismo Popular e Alternativo (ECA-USP)

Ano 10 Volume Ol Edição 23 Janeiro-Julho de 202l

Avenida Professor Lúcio Martins Rodrig̉ues, 443, Cidade Universitária, São Paulo, CEP: 05508-020 


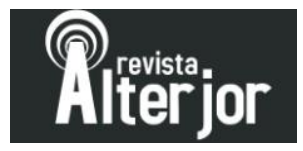

\section{REFLEXÕES INTRODUTÓRIAS}

A televisão vem exercendo uma importância função social, cultural, política, econômica e de desenvolvimento tecnológico no Brasil desde o dia 18 de setembro de 1950, data de sua inauguração. Não obstante, ao mesmo tempo que se observou o nascimento da televisão no País também pode ser visto o nascimento da linguagem jornalística na televisão: o telejornalismo. Em 19 de setembro de 1950, no dia seguinte, a PRF-3 TV Tupi de São Paulo, fundada pelo empresário dos Diários Associados Assis Chateaubriand colocou no ar o primeiro telejornal brasileiro intitulado "Imagens do Dia”. De acordo com Mello (2009), Neves (2015) e Silva (2018), esse telejornal se confunde com a própria história da televisão mostrando imagens brutas (sem edição) dos acontecimentos e tinha como característica as notícias lidas em formato de locução (marca oriunda do radiojornalismo), pelo locutor Ruy Rezende.

Ao comemorar 70 anos de existência da televisão e do telejornalismo no ano de 2020, entende-se que esse novo meio de comunicação e nova linguagem jornalística, tão popular e onipresente nos lares brasileiros, modificou a percepção e a relação com a sociedade. A presença do texto e do som acrescentou a imagem, que desde a década de 1950 foi sendo cada vez mais cultuada e registrando o seu lugar enquanto meio de comunicação massiva - ainda que em seus primórdios era feita para a ala mais elitizada da sociedade (RICCO; VANUCCI, 2017). Pois, “[...] vivemos uma era em que tudo concorre para a imagem, para a visibilidade e para a composição de sentidos no plano do olhar" (BUCCI; KEHL, 2004, p. 16).

Todavia, para além da amostra das primeiras imagens e a possibilidade técnica e tecnológica de uma nova linguagem e meio de comunicação, esta pesquisa se atenta para a questão da preservação desses registros, dessas memórias: o processo de arquivamento, acesso e uso do conteúdo audiovisual do telejornalismo no ambiente online. Com isso, tem-se o seguinte questionamento: como as transformações tecnológicas e socioculturais evidenciaram a necessidade de novas formas de arquivamento da informação audiovisual em ambientes digitais de informação?

O objetivo geral é identificar as transformações, desafios e oportunidades das inovações tecnológicas, frente ao processo histórico de suportes de armazenamento 
audiovisual. E como objetivos específicos: a) iniciar uma reflexão sobre a preservação do conteúdo jornalístico televisual e b) explanar sobre a utilização das mídias e ambientes digitais para a expansão do processo de arquivamento e preservação do telejornalismo. Assim, voltado para os estudos televisuais, este estudo também colabora para oportunizar uma explanação sobre este meio, no qual tanto se discute sobre as mudanças nas rotinas produtivas, narrativas, produção de conteúdos e inovações. Porém, pouco de discute sobre a sua preservação.

Neste sentido, será possível discutir sobre a necessidade de preservação dessas imagens, enquanto documentos telejornalístico que resguardam a história e a memória da sociedade. E além disso, discorrer sobre a necessidade de tornar acessível ao público o acesso e uso a tais documentos a partir dos novos suportes e processos tecnológicos frente aos ambientes digitais de informação (BRASIL, 2011; BRASIL; FRAZÃO, 2012; BRASIL; PAVLIK, 2016). A metodologia perpassa uma abordagem qualitativa, pesquisa bibliográfica e estratégia de pesquisa exploratória-descritiva, discorrendo sobre essas transformações e apresentando o Projeto Memória Globo como um lugar de memória audiovisual e jornalístico no universo digital.

\section{O NASCIMENTO DA TELEVISÃO E O TELEJORNALISMO}

O nascimento da televisão e o telejornalismo no Brasil ocorreu de fato em 1950, contudo o processo de inicia alguns anos antes, em 1946, quando o governo Dutra iniciou o processo de concessão e o grupo Diários Associados começou a trabalhar para implantar a televisão no País (RICO; VANUCCI, 2017). Desde então, sete décadas depois, eles têm sobrevivido às mudanças e transformações socioculturais, econômicas, políticas e tecnológicas ao passo que a sociedade também vislumbrou o mundo sendo dominado pela presença constante e contínua da imagem em movimento nas mais diferentes telas. A televisão não é apenas o veículo de comunicação mais assistido no Brasil, contudo, através de seus registros imagéticos ela também produz e resguarda uma construção memorialística social e nacional da sociedade brasileira: a memória midiática dos acontecimentos. 


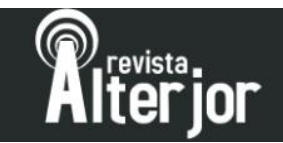

Para Silva (2018, p. 19), televisão e tecnologia caminham juntas quando se trata de forma e conteúdo e entende que "[...] não há dúvida de que a televisão e o jornalismo não possuem as mesmas práticas de 10, 20 ou 50 anos atrás". As implicações técnicas, sociais, culturais, econômicas e políticas, além das tecnológicas, impactaram no fazer televisão e jornalismo ao longo do processo histórico no Brasil e no mundo. Na Biografia da Televisão Brasileira Ricco e Vanucci (2017, sem paginação) explicam que

Com forte influência do rádio, o noticiário Imagens do Dia estreou em 19 de setembro, uma noite após a inauguração da TV Tupi. Com locução, redação e produção de Ruy Rezende, o pioneiro telejornal reunia os principais fatos do dia mesclando filmes gravados no período da tarde e fotografia, que cobriam a narração da notícia.

Devido à falta de equipamentos e tecnologias da época a telejornalismo era feito ao vivo, assim como toda a programação na TV, o que dificultava para a representação das informações em formato visual. Dessa forma, Silva (2011) destaca a presente atuação do cinejornalismo nos primeiros anos do telejornalismo uma vez que nos anos 1950 as imagens eram registradas em filme preto e branco, por cinegrafistas com experiência em filmes de ficção e documentários. Assim, destaca-se a junção de diversos profissionais na construção dos primeiros anos da TV e do telejornal.

Neves (2015, p. 25) destaca o caráter quase amador dos primeiros anos da nova linguagem jornalística, que estava sendo construída na TV: “[...] o telejornalismo tentava se inventar emprestando a linguagem verbal e imagética de outros veículos e a experiência dos profissionais do rádio". Assim, do telejornalismo ocorria de forma experimental e sob a presença de profissionais que já trabalhavam no cinema, o rádio e o jornalismo impresso. Neste sentido,

Os quase 70 anos da televisão brasileira foram construídos por muitos profissionais que talvez não planejassem atuar nesse veículo, mas que foram atraídos pela energia da inovação e pela magia de uma comunicação direta, ao vivo, em movimento e intensa, e, que não se preocuparam com o preconceito de quem atuava na mídias tradicionais e considerava a televisão o grande mal para a cultura do país, algo que deixaria o povo absolutamente alienado e burro (RICCO; VANUCCI, 2017, sem paginação). 


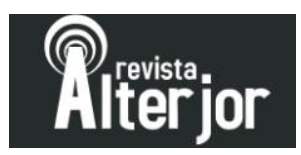

Não adentrando na discussão entre apocalípticos e integrados, apresentado por Umberto Eco (1995) em livro cujo título é o mesmo, é certo afirmar que esses diversos profissionais fizeram a televisão se tornar uma realidade e adquirir, com o passar do tempo, essa onipotência e onipresença que é possível identificar, ainda, em pleno século XXI mesmo com todas os questionamentos frente a sobrevivência dos meios de comunicação tradicionais. O poder de transformação dessa "telinha" que foi se expandido e se tornando presente nos mais diversos lugares, também pode ser observada em duas produções audiovisuais da década de 1980.

A primeira no filme Bye Bye Brasil, com direção de Cacá Diegues e lançado em 9 de fevereiro de 1980, em que logo nos primeiros minutos do filme um trupe circense chega numa pequena cidade do interior do País e sente a ausência da população. Tal ausência era marcada pela instalação da "televisão pública" na praça da cidade na qual a população estava hipnotizada assistindo a novela Dacing' Days da Rede Globo (1978); o segundo caso é representado pela novela Tieta, escrita por Aguinaldo Silva e lançada em 14 de agosto de 1989, que faz chegar na fictícia cidade de Santana do Agreste, interior baiano, uma caminhão, a "Arca dos Sonhos", com diversos aparelhos televisivos, simbolizando a chegada da tecnologia no interior do Brasil e a simbolização da presença da imagem como forma de "progresso", a partir da possibilidade de acompanhar o que se passava fora daquele lugar pela tela da televisão.

Já acerca do telejornalismo, Avancini (2001) ressalta que no início da televisão os primeiros formatos eram todos baseados naqueles já existentes na produção do rádio. Com isso, a primeira exibição de um telejornal no Brasil foi noticiado o desfile cívicomilitar pelas ruas de São Paulo. O programa tinha notícias locais lidas pelo locutor Ruy Rezende, que era também produtor e redator do jornal. As imagens eram produzidas em filme preto e branco pelos cinegrafistas Jorge Kurkjian, Paulo Salomão e Alfonso Zibas (REZENDE, 2000).

Na época, a programação da TV Tupi de São Paulo iniciava-se a partir das 20 horas e o telejornal não tinha um horário certo para ser veiculado, pois dependia da programação a ser exibida antes dele. Este fato pode ser constatado no anúncio publicado nos jornais do grupo Diários Associados, relativo à programação da PRF - 3 TV Tupi, de 20 de setembro de 1950. Todos os programas eram feitos ao vivo, pois não havia ainda o videoteipe (SILVA, 2011, p. 3, grifo nosso). 
A partir da construção de uma linguagem jornalística própria para a televisão, também coloca-se como uma questão a ser refletida o armazenamento e a preservação dessas imagens. Contudo, o que se percebe na leitura dos relatos e estudos que abrangem essa época é um foco na produção, sem uma sinalização sobre as questões de arquivamento da imagem televisiva. Esse fator pode ser associado a dois pontos: o fato da programação acontecer toda ao vivo e a falta de equipamentos tecnológicos à época para a gravação de imagens. Pois, o videoteipe só surgiria na década seguinte, em 1960, fazendo com que as primeiras imagens pudessem ser registradas para uma posterior visualização e arquivamento.

Com isso, uma preocupação que foi sendo modificada pela própria estrutura social e tecnológica, mas que pouco é suscitada no âmbito acadêmico. Neste sentido, ao direcionar este estudo desde o processo de arquivamento e preservação ao acesso e uso das imagens de arquivo busca-se versar luz para uma problemática pouco explorada no campo da Comunicação.

HISTORICIDADE DOS SUPORTES DE ARQUIVAMENTO AUDIOVISUAL

Para entender o processo de arquivamento e preservação da memória do telejornalismo se faz preciso de antemão voltar ao tempo e investigar o surgimento, as transformações e modificações das técnicas e suportes tecnológicos de arquivamento audiovisual. Do cinema às novas mídias esses suportes sofreram uma diminuição das suas dimensões, tipo de material utilizado e dispositivo de acesso, ao qual a mídia audiovisual necessita para ser reproduzida. Ou seja, a preservação perpassa tanto o conteúdo em si, quanto o seu dispositivo num movimento duplo e que ocorre conjuntamente: o documento audiovisual contido num arquivo e o seu dispositivo como um projeto, videocassete, aparelho de DVD entre outros.

De acordo com Edmondson (2017), os arquivos audiovisuais estabelecem duas proposições: a) o processo de arquivamento e b) as tipologias de arquivo existentes. A partir de tais proposições entende-se que o "[...] arquivamento audiovisual acontece em uma ampla gama de tipos de instituição e está em constante desenvolvimento à medida que se expandem as possibilidades de distribuição física e digital" (EDMONDSON, 


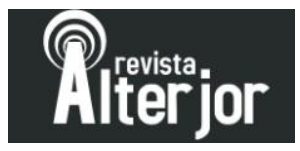

2017, p. 33), ou híbrida. Isso pode ser observado a partir das organizações jornalísticas como, por exemplo, os telejornais que ao longo do tempo foram adaptando e transformando o seu processo de arquivamento audiovisual do ambiente físico para o on-line e estabelecendo outro fluxo de informação.

Em relação a tipologia, Edmondson (1998) organiza os tipos de arquivo de acordo com a sua funcionalidade e características (quadro 1) possibilitando a visualização de cada um dos tipos existentes:

Quadro 1 - Tipologia e categorização dos arquivos audiovisuais

\begin{tabular}{|c|c|}
\hline Tipo de arquivo & Descrição \\
\hline Arquivos de emissoras & $\begin{array}{l}\text { Contêm principalmente um inventário de programas } \\
\text { de rádio e/ou televisão selecionados e gravações de } \\
\text { comerciais guardadas para propósitos de emissão. }\end{array}$ \\
\hline Arquivos de programação & $\begin{array}{l}\text { São arquivos de filme ou arquivos de televisão bem } \\
\text { caracterizados em primeiro lugar por uma ênfase na } \\
\text { qualidade no plano da investigação e da apresentação } \\
\text { nos seus próprios écrans ou salas de exibição como } \\
\text { meio de acesso público. }\end{array}$ \\
\hline Museus audiovisuais & $\begin{array}{l}\text { O foco dessas organizações é a preservação e exibição } \\
\text { de artefatos como máquinas fotográficas, projetores, } \\
\text { fonógrafos, cartazes, publicidade e efêmera, fantasias } \\
\text { e a apresentação de imagens e sons num contexto de } \\
\text { exibição público, ambos com propósitos educacionais } \\
\text { e de entretenimento. }\end{array}$ \\
\hline Arquivos audiovisuais nacionais & $\begin{array}{l}\text { São organizações de largo âmbito, frequentemente } \\
\text { grandes, operando ao nível nacional, com umobjetivo } \\
\text { de documentar, preservar e tornar publicamente } \\
\text { acessível o todo - ou uma parte significante - do } \\
\text { património audiovisual do país. }\end{array}$ \\
\hline Arquivos acadêmicos e universitários & $\begin{array}{l}\text { Em todo o mundo, há numerosas universidades e } \\
\text { instituições acadêmicas que possuem arquivos } \\
\text { sonoros, filme, vídeo ou audiovisual em geral. }\end{array}$ \\
\hline Arquivos temáticos e especializados & $\begin{array}{l}\text { Este também é um grupo grande e variado de arquivos } \\
\text { que não tratam do património audiovisual em geral, } \\
\text { mas ao contrário optaram por uma clara e às vezes alta } \\
\text { especialização. }\end{array}$ \\
\hline Arquivos de estúdios & $\begin{array}{l}\text { Algumas das maiores produtoras, por exemplo na } \\
\text { indústria de filme, levaram a cabo uma abordagem } \\
\text { consciente à preservação da sua própria produção } \\
\text { criando unidades de arquivo ou divisões dentro das } \\
\text { suas organizações. }\end{array}$ \\
\hline
\end{tabular}




\begin{tabular}{|c|l|}
\hline Arquivos regionais, municipais e locais & $\begin{array}{l}\text { Operam normalmente a um nível regional ou local. } \\
\text { Podem surgir de circunstâncias particulares, } \\
\text { administrativas ou políticas governamentais (como } \\
\text { programas de descentralização) os seus objetivos } \\
\text { tenderão a ser focalizados de acordo com a sua } \\
\text { natureza. }\end{array}$ \\
\hline Grandes coleções & $\begin{array}{l}\text { Este é grupo mais difícil para descrever, mas, no } \\
\text { entanto, um grupo também susceptível de ser } \\
\text { reconhecido. Pode incluir arquivos em quaisquer das } \\
\text { categorias precedentes que ganharam dimensão pela } \\
\text { sua qualidade, riqueza, coesão ou raridade das } \\
\text { propriedades. }\end{array}$ \\
\hline
\end{tabular}

Fonte: Edmondson (1998).

Em conjunto com a apresentação das tipologias e características dos arquivos audiovisuais como forma de identificar as possibilidades existentes, busca-se também contemplar os seus suportes de arquivamento e dispositivos de acesso, enquanto foco do presente estudo, pois são nestes suportes que os conteúdos são armazenados para uma posterior recuperação e acesso à informação audiovisual, sobretudo a informação jornalística televisual. A partir disso, a seguir apresenta-se uma historicidade da evolução dos suportes de armazenamento audiovisual desde o século 19:

Quadro 2 - Historicidade dos suportes para arquivos audiovisuais

\begin{tabular}{|c|c|c|c|}
\hline Categoria & Suporte & Dispositivo & Período \\
\hline Fotoquímico/Fílmicos & $\begin{array}{l}\text { Película de Nitrato } \\
\text { Película de Acetato } \\
\text { Película de Poliéster }\end{array}$ & Projetor & Entre 1880 a 1990 \\
\hline Fitas Magnéticas & $\begin{array}{c}\text { Analógica } \\
\text { Fitas quadruplex } \\
\text { U-matic } \\
\text { VHS } \\
\text { FitaSuperVHS } \\
\text { Digital } \\
\text { Beta SP } \\
\text { Beta Digital } \\
\text { Fita DV ou Digital Vídeo } \\
\text { Mini-DV } \\
\text { DVCAM }\end{array}$ & Vídeo Cassete & Entre 1950 a 1990 \\
\hline
\end{tabular}




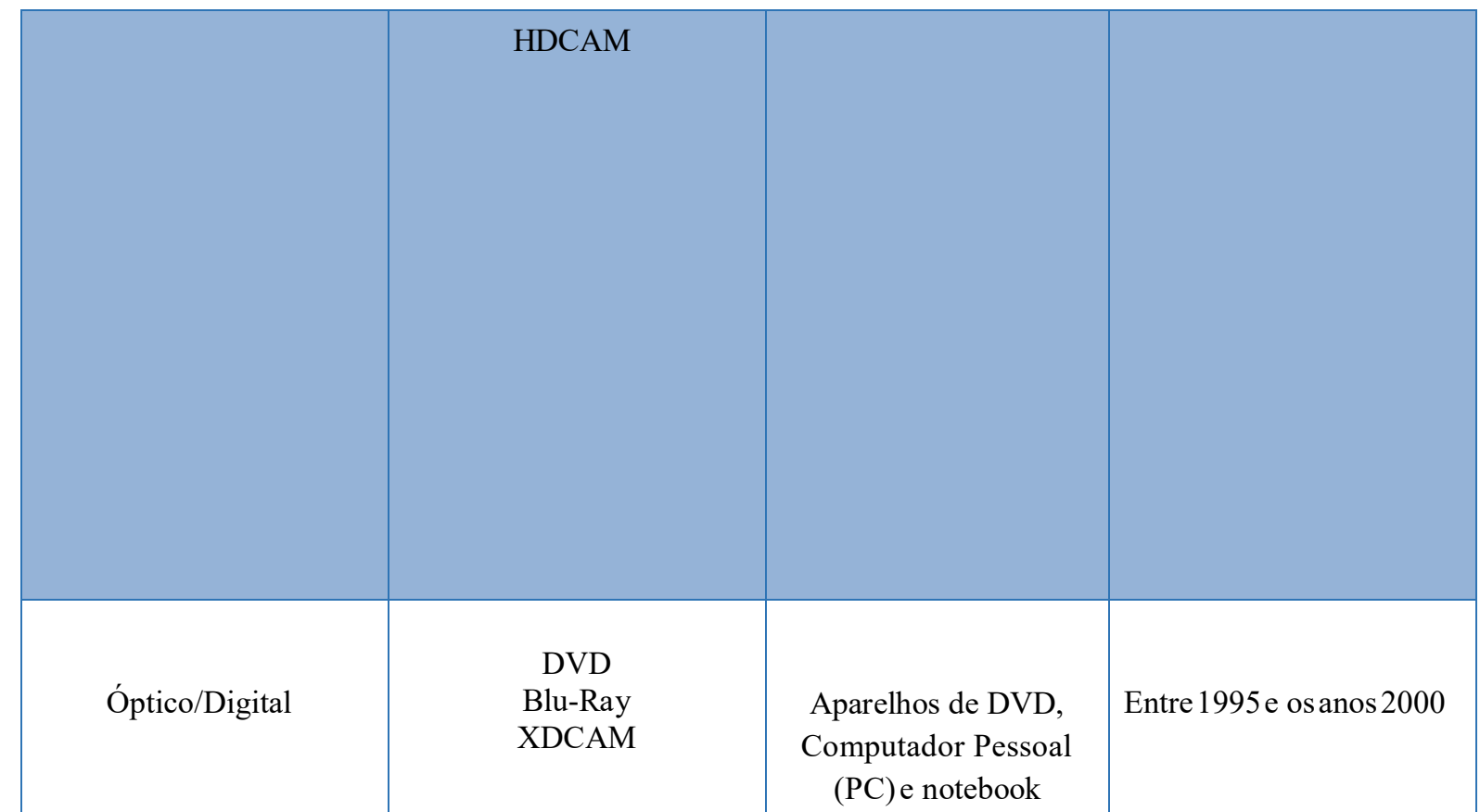

Fonte:Elaboração própria (2020).

Esse quadro possibilita a averiguação das transformações históricas dos suportes tecnológicos utilizados para o arquivamento e salvaguarda dos conteúdos audiovisuais, abrangendo diversas possibilidades de atuação como o cinema, televisão e as mídias digitais. Observa-se, então, que desde o século XIX, passando pelo século XX e adentrando o século XXI os suportes, dispositivos e técnicas de armazenamento e preservação foram sendo modificados e passando por um processo de miniaturização dos suportes (da película, para a fita e posteriormente para o formato em DVD). Além disso, com a chegada da internet e da revolução ocasionada pela Era Digital, ferramentas e artefatos digitais, atualmente, que reestruturam as formas de armazenamento como os arquivos em "nuvens" - arquivos digitais que são não materializados e que trafegam pela rede on-line em questão de minutos ou mesmo segundos.

Assim, vale ressaltar a concepção de Satuf (2016) na qual o autor visualiza o ciberespaço com base na metáfora da "nuvem" e, que se aplica sob a condição do armazenamento de memória dos arquivos audiovisuais em ambiente digitais. Essa metáfora altera por completo a noção clássica de ciberespaço, observada na obra de ficção científica William Gibson "Burning Chrome”, em 1982. Neste sentido, a nuvem 


\section{ARerior}

“[...] não se apresenta como barreira nem interface através da qual o usuário é transportado de um lugar para outro. Ela 'paira' permanentemente sobre os inúmeros pontos errantes interconectados e 'respinga' informação no fluxo da vida ordinária" (SATUF, 2016, p. 211).

Diante tais transformações, evidencia-se a necessidade de aprofundamento e alargamento da discussão sobre os processos e as técnicas de armazenamento e salvaguarda dos conteúdos e produtos audiovisuais, especificamente devido a obsolescência dos equipamentos e a necessidade do uso de um dispositivo de acesso para a sua reprodução. O que acarreta, neste sentido, numa preocupação a mais, pois é necessário além de manter um cuidado com o produto em si se faz preciso também atentar-se para o seus dispositivo de reprodução.

Essa mesma preocupação é direcionada, neste estudo, para os arquivos de telejornalismo vistos como produtos de informação da sociedade e, que resguardam a história e a memória cotidiana sob o viés midiático. Não almeja-se com este estudo debruçar-se sobre as questões éticas, direcionamentos políticos, ideologias e intencionalidades desse conteúdo - que também necessitam ser refletidos. Contudo, objetiva-se explanar que o jornalismo funciona como um lugar de memória (NORA, 1993) e entender que ele "[...] nos dá a dimensão daquilo que devemos lembrar e o que deve ser esquecido" (MUSSE; THOMÉ, 2016, p. 67). E, também, da forma como esse passado é resguardado para ser (re)apresentado, acessado e usado pela sociedade.

\section{O ARQUIVAMENTO, ACESSO E USO DA MEMÓRIA TELEJORNALÍSTICA}

Ribeiro, Souza e Gomes (2017) destacam que o papel midiático está em constante afirmação de um tempo presente, de uma imediaticidade, do "tempo real", um "sempre novo" ou em estado de sempre novo. Essa percepção apresentada pelos autores direciona para a discussão do processo de arquivamento da imagem telejornalística. Aqui, o arquivo é visto como esse organismo vivo e sempre novo, apresentando de tempos em tempos e a cada novo olhar uma forma simbólica de compreender os fatos e acontecimentos de outrora - uma questão subjetiva e permeada de questões pessoais, 


\section{Preitior}

que culminam em interpretações diferentes de um mesmo objeto, a partir da interpretação individual.

Todavia, essa face só é possível mediante a realização de três características: (1) o vislumbre do processo de arquivar, (2) de tornar acessível e por fim, (3) do uso que é feito destas imagens. Essas três operacionalidades acerca da memória telejornalística perpassam a discussão neste artigo e que se opera a partir dos estudos de Brasil e Frazão (2012) e Brasil e Pavlik (2016). Os autores apresentam em seus respectivos estudos apontamentos para discorrer sobre a disponibilização, acesso e uso destes arquivos de telejornais. Já a questão do arquivamento audiovisual é uma temática a ser discutida sob as potencialidades dos ambientes digitais, da facilitação para o tráfego das informações e da necessidade de preservar essas imagens para a sua recuperação na contemporaneidade.

No telejornalismo esse arquivamento já ocorre, porém possui algumas especificidades próprias e que devem ser problematizadas. $\mathrm{O}$ arquivo de imagens pode ser dividido em duas categorias: o arquivo de imagens brutas e o arquivo de imagens tratadas e editadas como, por exemplo, as edições das reportagens, matérias, séries especiais, documentários e a própria edição finalizada do telejornal. Inicialmente, ambos os arquivos eram de cunho interno e o acesso a esses registros, para consulta e pesquisa externa, ocorria (e em parte ainda ocorre) mediante a solicitação e a um tempo de espera pela resposta da empresa até, possivelmente, uma autorização e acesso aos arquivos do telejornal pelos sujeitos externos.

Porém, com o avanço das tecnologias digitais, a introdução da internet e dos novos meios de comunicação no ciberespaço novos modelos e propostas de arquivamento no âmbito on-line foram surgindo e possibilitando novas dinâmicas e, também, um abertura frente ao processo de comunicação entre os atores internos do telejornal e os atores externos. O que sugere também a diminuição das barreiras de acesso e uso dos arquivos de telejornais via redes digitais, facilitando a recuperação da informação e o uso de tais imagens. Essa ideia pode ser vislumbrada, por exemplo, ao pensar num sistema de memória ou banco de dados que possam agregar informações 


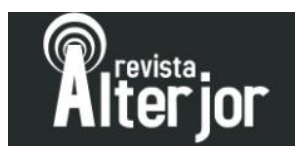

entre as emissoras afiliadas e a emissora em rede, ocasionando no uso de imagens numa velocidade mais rápida de acontecimentos que se tornam nacionais.

Brasil (2011) explicita a necessidade dos arquivos de telejornais estarem acessível ao público externo, uma vez que esses arquivos ainda estão concentrados em arquivo de documentação privado das emissoras de televisão. Com isso, os arquivos se

[...] apresentam como uma fonte primária, documentando eventos históricos específicos e cotidianos. Apesar do valor histórico, materiais noticiosos estão entre os mais ameaçados de extinção, são altamente subestimados e menos procurados em coleções de imagens em movimento (BRASIL; PAVLIK, 2016, p. 31).

Esse fato sugere que há uma carência de investigações e discussão em torno desse objeto de pesquisa. Porcello, Ihitz e Peixoto (2015, p. 1), ao argumentarem sobre a importância da preservação adequada dos registros telejornalísticos, explicam que "[...] constata-se com tristeza que os registros desde os tempos mais remotos até os mais atuais são escassos e insuficientes para resgatarmos com precisão a história brasileira deste período". Essa dificuldade apontada pelos autores é pouco identificada na literatura sobre a área, demonstrando pouca preocupação com a questão da preservação e salvaguarda.

Desta forma, as "cenas televisivas são também um importante registro de nossa própria cultura e nossa memória social” (BRASIL; PAVLIK, 2016, p. 32). E dentre essas cenas as imagens telejornalística compõem uma parcela importante e fundamental da representação dos acontecimentos da história e da memória da humanidade, que no Brasil já ocorre há 70 anos. Neste sentido, a compreensão sobre as transformações técnicas e tecnológicas do arquivamento dessas imagens é uma discussão pertinente e atual, pois objetiva a visualização dessa memória capturada e registrada pelas lentes das câmeras jornalísticas.

Nesse entremeio, Souza e Cajazeira (2020) argumentam sobre a necessidade da implantação de uma cultura do arquivamento. Mas, o que é a cultura do arquivamento audiovisual? De acordo com os autores,

Trata-se de desenvolver os ideais de acesso, uso, disseminação e recuperação da informação. É o estabelecimento de diretrizes e de um modelo de 


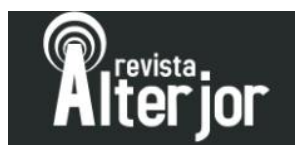

organização que tem como finalidade a preservação de documentos audiovisuais, a partir de uma série de atividades práticas que até já podem ser vistas nos ambientes de informação, mas que não possui uma prática constante ou um fluxo de funcionamento mais ativo (SOUZA; CAJAZEIRA, 2020, p. 77).

O objetivo da cultura do arquivamento é a implantação de uma organização e prática cotidiana de preservação da imagem, nos ambientes informacionais que possuem e lidam com o audiovisual, a exemplo do telejornalismo e programas jornalístico. Desa forma, o objetivo não é apenas armazenar, mas

[...] a salvaguarda para que exista o acesso, a disseminação, a recuperação e o uso da informação audiovisual. É mais do que um hábito de realizar o arquivamento dessas produções; é dar visibilidade para esse tipo de documento e criar um sistema próprio de memória (SOUZA; CAJAZEIRA, 2020, p. 77).

Deste modo, correlaciona-se a cultura do arquivamento audiovisual com a função social desses lugares de memória (NORA, 1993) para o armazenamento e a disponibilização on-line do conteúdo audiovisual telejornalístico, partindo do uso das tecnologias e dos ambientes digitais. Uma vez que "[...] no cenário contemporâneo a emergência de novas formas e representações do passado, traduzidas em iniciativas de resgate e preservação da história e da memória" (SANTOS; FERNANDES, 2020, p. 220). E uma das dessas formas está representada pelas imagens de arquivos de telejornais, armazenadas a partir de estratégias de arquivamento on-line a exemplo do site Memória Globo.

\section{PROJETO MEMÓRIA GLOBO}

O Projeto Memória Globo foi criado em 1999, com o intuito de resgatar e contar a história do Grupo Globo ${ }^{2}$. Neste projeto digital essa memória é composta por diferentes e diversas linguagens como reportagens escritas, fotografias, vídeos e o uso da memória oral trazendo declarações de diversas personalidades que fizeram parte, em algum momento da história, do Grupo Globo seja atuando em novelas e minisséries,

\footnotetext{
${ }^{2}$ Essa informação está disponibilizada em: https://memoriaglobo.globo.com/quem-somos/. Acesso em: 26 ago. 2020.
} 


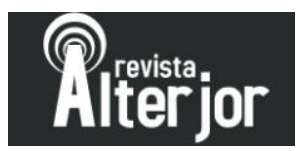

seja apresentando os telejornais, fazendo uma cobertura internacional ou atuando nos bastidores criando e dirigindo a programação.

Ao adentar na plataforma, o menu oferece o seguintes tipos de conteúdo: Entretenimento; Jornalismo; Esporte; Perfis; Erros; Acusações falsas; Exclusivo Memória Globo e Memória.Doc. Detendo-se somente ao caráter do Jornalismo, especificamente do telejornalismo, o site contempla a história do telejornalismo da empresa a partir de três formas de arquivamento: (1) telejornais e programas; (2) coberturas e (3) a Globo News - sua emissora de televisão a cabo.

Conforme proposto neste estudo o objetivo é apresentar essa plataforma on-line como resultado dos processos de transformações do arquivamento e da abertura do acesso e uso à informação e imagem telejornalismo, ainda que parcialmente, para o usuário externo. A averiguação dessa abertura é uma das potencialidades oriunda da realidade da comunicação digital, do aumento da velocidade do tráfego da informação e do compartilhamento desses dados, que anteriormente estavam restritos nos Centros de Documentação e Arquivo dos telejornais necessitando de todo um processo de solicitação para o uso.

Nesta perspectiva, a introdução dos arquivos de telejornais no ambiente digital remodela as relações estabelecidas entre usuários externos e profissionais do setor de arquivo da organização jornalística, bem como da visualização da construção da memória midiática pelo telejornalismo brasileiro. Com isso, compreende-se que se no século XIX o conteúdo audiovisual era armazenado e arquivado em películas fílmicas, percorrido dois séculos esses arquivos foram realocados para novos formatos e inseridos em "nuvens digitais" dentro de um sistema de memória e banco de dados on-line.

Esse processo pode ser exemplificado com o telejornal mais antigo da televisão nacional e que ainda permanece presente na contemporaneidade: o Jornal Nacional. A sua primeira exibição ocorreu em $1^{\circ}$ de setembro de 1968 , ou seja, há mais de 50 anos e a partir dos seus registros de imagens é possível compreender que este telejornal apresenta todas as mudanças e reestruturações técnicas e tecnológicas de produção de um telejornal brasileiro. Passando da imagem em preto e branco, para a colorida; das transformações de um cenário fixo para o interativo; da quebra da "quarta parede" 


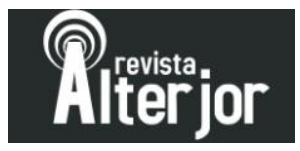

agregando a redação como parte do telejornal; a movimentação dos apresentadores pelo estúdio e de equipamentos e artefatos tecnológicos que aproximam o telejornal do seu público, os arquivos de imagens de telejornais são capazes de narrar essa história através dos documentos audiovisuais.

A memória das transformações tecnológicas e socioculturais do telejornalismo se apresenta em diversos momentos no site Memória Globo. No que se refere ao Jornal Nacional o usuário pode navegar nos arquivos de imagem, por exemplo, sobre as transformações do uso das tecnológicas na produção do telejornal a partir de uma linha do tempo. Das reportagens ao textos de apresentação, das fotografias aos depoimentos de personalidades que estiveram presentes, vivenciando as mudanças do audiovisual esses arquivos vão sendo despidos e revelando as informações para que seja possível identificar e compreender as reconfigurações no fazer telejornalístico.

$\mathrm{O}$ acesso aberto e gratuito a esses arquivos de imagens disponibilizadas na internet é um passo fundamental e importante, que estabelece condições atuais de apropriação da informação para o usuário externo. Para pesquisadores da área esse passo representa uma inicial ruptura do acesso a esses arquivos e para o público geral uma possibilidade de manutenção com essas memórias. Curiosidades, dúvidas e rememorações estão, agora, disponibilizadas on-line. Isso não significa que todo o conteúdo foi transposto. É nítido que há uma seleção, uma hierarquização das informações que estão disponibilizadas para acesso livre. O que sugere uma análise crítica em estudos futuros, analisando o que está disponível e aquilo que não foi disponibilizando para averiguar as implicações do processo de arquivamento e migração digital.

Contudo, atentando-se ao lado positivo deste procedimento, ao identificar a abertura, a migração e o arquivamento realizado direto nas plataformas digitais de informação pode-se aferir para uma preocupação contemporânea de acesso à informação em caráter público pelas emissoras de televisão e pelo núcleo de telejornalismo. O caso do Memória Globo é apenas esse início, ainda carente de problematizações. Porém, apresentando-se como esse lugar de memória na esfera digital no qual torna-se visível as mudanças no telejornalismo brasileiro. 


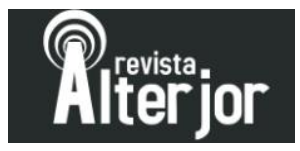

Neste sentido, os processos de arquivamento, acesso e uso dos arquivos audiovisuais de telejornais têm sido ressignificados com as transformações tecnológicas e, sobretudo, da percepção das organizações jornalísticas em compartilhar a produção telejornalística em plataformas e ambientes digitais de informação. Um avanço que tem diminuído as barreiras de acesso à informação audiovisual jornalística e possibilitado o vislumbre dessas memórias que estavam apenas disponíveis nos centros de documentos e arquivos das emissoras de TV.

\section{CONSIDERAÇÕES FINAIS}

A preservação dos arquivos de telejornalismo e as possibilidades de acesso e uso das imagens pelos usuários externos ao telejornal, ainda é uma realidade em transformação. Como destacado no estudo, o processo de arquivamento não é recente, contudo ele estava direcionado apenas ao ambiente interno do telejornal e da empresa de comunicação. Ao direcionar a busca por uma ampliação das atividades de preservação e arquivamento no âmbito on-line, foi possível constatar com o caso do Projeto Memória Globo que há duas vertentes ocorrendo simultaneamente, ainda que não muito em evidência: a) a preocupação em criar um sistema de memória em ambientes digitais e b) ao mesmo tempo disponibilizar e compartilhar essa memória com o usuário externo.

Assim, frente ao histórico dos suportes de armazenamento audiovisual, o que se averigua com a introdução do arquivamento on-line é uma readaptação e reordenamento dos sistemas de armazenamento da memória telejornalística. Pois, há uma diluição das barreiras de acesso e uso, ainda que parciais e, também inserem a reflexão de questões éticas, de domínio e direito das imagens e usos pela comunidade externa ao telejornal e a empresa de comunicação - uma temática para ser explorada em estudos futuros.

$\mathrm{O}$ arquivamento das imagens já ocorria, mas sob a lógica da informação privada e apenas disponibilizada quando solicitada, sobretudo, por pesquisadores em telejornalismo. Esse processo é marcado pela dificuldade de obtenção dos documentos, já que é preciso enviar uma solicitação explicitando os motivos do uso dessas imagens, aguardar o processamento do pedido e, por fim, ainda correr o risco de ter o acesso 


\section{Rireiorior}

negado. O seu uso também ocorre para fins interno, seja das imagens brutas, seja das imagens já tratadas como pode-se identificar em programas e reportagens que se utilizam dessas imagens de arquivos para rememorar um acontecimento passado ou dialogar com os fatos do presente.

O estudo, assim, enxerga a necessidade dessa expansão que aos poucos vem sendo uma realidade identificada a exemplo dos sites de telejornais que arquivavam e disponibilizavam as reportagens do dia a dia no ambiente digital. Porém, de modo limitado sem, por exemplo, a possibilidade de fazer download do vídeo. Posteriormente, tem-se uma construção e percepção dessas imagens como objeto de memória e a criação de lugares como o Projeto Memória Globo, abarcando não somente o registro dessas imagens, mas trazendo seus colaboradores para reviver esses momentos e contar curiosidades dos bastidores. Além disso, essas arquivos têm funcionado como modelos de negócio do campo audiovisual a exemplo do serviço de streaming Globoplay que se utiliza do seu material já produzido para alcançar novas audiências e assinantes.

Desse modo, esses registros de imagens revelam as transformações sociais, culturais, políticas, econômicas e tecnológicas do fazer telejornalístico. Das primeiras imagens ao vivo no início da televisão e do telejornalismo em 1950 aos atuais recursos de interação e disponibilização em dispositivos móveis de acesso, o telejornalismo acopla mudanças que extrapolam as questões estruturais. Essas mudanças adentram o cotidiano de cada sujeito, de cada telespectador sendo um formato presente a 70 anos na televisão brasileira e apresentando diversas novidades como a inserção da redação como parte do cenário do telejornal, o uso de recursos gráficos em realidade aumentada e 3D, telas de LED em tamanho real, uso das redes sociais para a interação e a própria postura menos sisuda do telejornalista no cenário que agora até anda pelo espaço e não permanece apenas sentado na tradicional bancada.

Da era analógica para a digital, os arquivos de telejornais propiciam maior contato com o passado não somente da televisão e do telejornalismo, mas com as transformações da sociedade, da cultura, dos costumes e das lutas enfrentadas pelos nossos familiares, amigos e personagens históricos. É um memória viva, registrada em movimento e que ao ser compartilhada evoca e suscita o entrelaçamento entre gerações, 


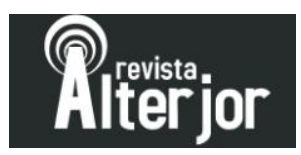

temporalidades e acontecimentos do ontem que refletem no hoje e, consequentemente, no amanhã.

Nesta perspectiva, o arquivamento, a disponibilização e o acesso aos arquivos de telejornais em ambientes digitais evoca mudanças e transformações do uso dessas imagens de arquivos, ao estabelecerem um contato mais imediato e direto com o usuário externo. Além disso, os desafios e oportunidades das inovações tecnológicas a partir dos novos suportes e artefatos da era digital ofertam diferentes ferramentas e técnicas de preservação, uso dos dispositivos digitais e a facilidade do tráfego da informação, visualizados como um lado positivo dos ambientes digitais.

\section{REFERÊNCIAS}

AVANCINI, Walter. A marca do diretor. In: SILVA JÚNIOR, Gonçalo. País da TV: a história da televisão brasileira por. São Paulo: Conrad Editora do Brasil, 2001.

BRASIL, Antonio; PAVLIK, John V. Big data, código computacional e arquivos de notícias televisivas: implicações dos avanços nos métodos de investigação audiovisual para a qualidade do jornalismo. Parágrafo, São Paulo, v. 4, n. 2, jul./dez., 2016.

BRASIL, Antonio. Dificuldades, limites e novas propostas para o acesso livre aos arquivos de telejornalismo brasileiros. In: SEMINÁRIO INTERNACIONAL DE

ANÁLISE DE TELEJORNALISMO: DESAFIOS TEÓRICO-METODOLÓGICOS, 10., 2011, Salvador. Anais [...], Salvador, 2011. Disponível em: https://analisedetelejornalismo.files.wordpress.com/2011/08/brasil_antonio.pdf. Acesso em: 22 abr. 2020.

BRASIL, Antonio; FRAZÃO, Samira. Reflexões sobre o acesso aos arquivos de telejornais brasileiros. Famecos, Porto Alegre, v. 17, n. 28. 2012.

ECO, Umberto. Apocalípticos e integrados. 5. ed. São Paulo: Perspectiva, 1993.

EDMONDSON, Ray. Arquivística audiovisual: filosofia e princípios. Trad. de Carlos Roberto Rodrigues de Souza. - Brasília: UNESCO, 2017.

MELLO, Jaciara Novaes. Telejornalismo no Brasil. Covilhã: BOOC, 2009.

MUSSE, Christina Ferraz; THOMÉ, Cláudia. Telejornalismo e poder: memórias (re)construídas pelo "Jornal Nacional”. In: EMERIM, Cárlida; FINGER, Cristiane; PORCELLO, Flávio. Telejornalismo e poder. Coleção Jornalismo Audiovisual. v.5. Florianópolis: Insular, 2016. p. 65-83.

NEVES, Flora; Telejornalismo nos primeiros tempos: história de desafios. In: VIZEU, Alfredo; MELLO, Edna; PORCELLO, Flávio; COUTINHO; Iluska. (org.). Telejornal e praça pública: 


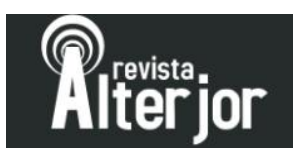

65 anos de telejornalismo. Coleção Jornalismo Audiovisual. v. 4. Florianópolis: Insular, 2015. p. 25-48.

PORCELLO, Flávio; IHITZ, Greetchen Ferreira; PEIXOTO, Filipe. Arquivos do Telejornalismo: a memória fragmentada dos 65 anos de TV no Brasil. In: ENCONTRO NACIONAL DE HISTÓRIA DA MÍDIA, 10., 2015, Porto Alegre. Anais [...], Porto Alegre, 2015. Disponível em: http://www.ufrgs.br/alcar/encontros-nacionais1/encontros-nacionais/10o-encontro-2015/gt-historia-da-midia-audiovisual-evisual/arquivos-do-telejornalismo-a-memoria-fragmentada-dos-65-anos-de-tv-nobrasil/at_download/file. Acesso em: 18 abr. 2020.

REZENDE, Guilherme Jorge de. Telejornalismo no Brasil: um perfil editorial. São Paulo: Summus, 2000.

RIBEIRO, Ana Paula Goulart; SOUZA, Bruno; GOMES, Itania. A historicidade dos processos comunicacionais: elementos para uma abordagem. In: MUSSE, Christina Ferraz; VARGAS, Herom; NICOLAU, Marcos. (orgs.). Comunicação, mídias e temporalidades. Salvador: EDUFBA, 2017.

RICCO, Flávio; VANUCCI, José Armando. Biografia da televisão brasileira. 1. ed. São Paulo: Matriz, 2017.

SANTOS; Larissa Conceição dos; FERNANDES, Fábio Frá. Desafios à preservação da memória cultural no Brasil: um estudo no município de São Borja/RS. Revista Brasileira de Mídia, Teresina, v. 9, n. 1, jan./jun., 2020. Disponível em: https://revistas.ufpi.br/index.php/rbhm/article/view/8566/6418. Acesso em: 25 ago. 2020.

SATUF, Ivan. Onde está o ciberespaço? A metáfora da "nuvem" aplicada aos estudos da cibercultura. Ação Midiática, Curitiba, n.11, p. 201-220, jan/jun., 2016.

SILVA, Edna de Mello. As imagens do telejornal Imagens do Dia: a influência do cinejornalismo e do rádio na primeira fase do telejornalismo brasileiro. In: ENCONTRO NACIONAL DE HISTÓRIA DA MÍDIA, 8., 2011, Guarapuava. Anais [...], Guarapuava: UNICENTRO, 2011.

SILVA, Edna de Mello. Fases do telejornalismo: uma proposta epistemológica. In: EMERIN, Cárlida; COUTINHO, Iluska; FINGER, Cristiane. (orgs.). Epistemologias do telejornalismo brasileiro. Coleção Jornalismo Audiovisual. v. 7. Florianópolis: Insular, 2018. p. 19-36

SOUZA, José Jullian Gomes de; CAJAZEIRA, Paulo Eduardo Silva Lins. Cultura do arquivamento audiovisual: armazenamento, acesso e recuperação da informação em ambientes digitais. Ci. Inf. Rev., Maceió, v. 7, n. 1, p. 71-85, jan./abr. 2020. Disponível em: http://www.seer.ufal.br/index.php/cir/article/view/9529. Acesso em: 10 jun. 2020. 